\title{
Three Complex Prepositions with And
}

\author{
Hideo Hirao ${ }^{1}$ \\ ${ }^{1}$ College of Policy Science, Ritsumeikan University, Kyoto, Japan \\ Correspondence: Hideo Hirao, College of Policy Science, Ritsumeikan University, 56-1 Tojiinkitamachi Kitaku \\ Kyoto, 603-8577, Japan. Tel: 81-75-465-7877. E-mail: hideh@maia.eonet.ne.jp
}

Received: January 24, 2013 Accepted: February 25, 2013 Online Published: March 25, 2013

doi:10.5539/ijel.v3n2p25

URL: http://dx.doi.org/10.5539/ijel.v3n2p25

This paper is based on the presentation read at the 6th meeting of Japan Society for Phraseology held at Umeda Campus, Kwanseigakuin University, Japan on September 22, 2012.

\begin{abstract}
The discussion on complex prepositions has been centered on the string whose structure is preposition plus nominal plus preposition (PNP). However, there are other strings whose internal structures are quite distinct from the above and which are undergoing the process of grammaticalization and should be treated as single grammatical components, i.e. complex prepositions, in given circumstances where they appear. Three of those are up and above, down and below, and from top to bottom and across. They all share one characteristic that they have and in the second final position before the string final prepositions. They all appear in almost every circumstance where a single word preposition may appear. In addition, they all can be used as prepositional adverb which is a prominent major derivational use of single word prepositions.
\end{abstract}

Keywords: complex preposition, grammaticalization, corpus

\section{Introduction}

\subsection{Complex Preposition as a Part of Grammaticalization}

Grammaticalization is a process by which content words become grammatical items(Hopper \& Traugott, 1993, 2003) In English there are a number of complex prepositions where prepositions and adverbs combine together and form single word prepositions, i.e. into, onto, upon, within, without, although the status of items which are considered as adverbs in these instances may be a little bit controversial. The fact is, they have already completed grammaticalization process and become single lexical items.

What has gathered attention was the existence of $\mathrm{PREP}_{1}+\mathrm{NOUN}+\mathrm{PREP}_{2}(\mathrm{PNP})$ complex prepositions (Quirk et. al., 1972). Since strings of three items are claimed to form grammatical units on their own, their level of grammaticalization posed delicate questions whether they really are functioning as real grammatical entities.

\subsection{Previous Discussions}

The existence of complex prepositions consisting of PNP was noted by Quirk \& Mulholland (1964). Seppanen, Bowen \& Trotta (1994) refuted the existence of complex prepositions and claimed that they are instances of free forms. Hoffmann (2005), on the basis of vast corpus study, illustrated that they are actually grammatical units.

What has been absent in their scope of discussion was that there are other strings whose internal structures are quite different and which have gone through the process of grammaticalization and begun to function as complex prepositions. Inoue (2012) has indicated two instances of such fixed expressions.

\subsection{Three Other Complex Prepositions}

There are still other complex prepositions. Three of which are up and above, down and below, and from top to bottom and across. They all exhibit distribution patterns which are quite close to those of single word prepositions. In addition, they all can be used as prepositional adverbs. Thus, their unity as integrated strings is even stronger than PNP complex prepositions which can rarely be used as such.

\subsection{Tests by Linguistic Functions}

A single word preposition acts as a head of a prepositional phrase. This prepositional phrase is used for a number 
of linguistic functions. Among them are:

(1) Predicative Nominal Modifier

a cup on the table

(2) Intransitive Verb Complement

The building stands at the corner.

(3) Transitive Verb Complement

I put the car into the garage.

In addition, a major derivational use of single word prepositions is a prepositional adverb.

We stayed on.

If a string in question can be used in all of these functions, it can be considered as a strong candidate for a complex preposition.

\section{Distribution Patterns of Three Complex Prepositions with And}

In this section, distribution patterns of three complex prepositions, up and above, down and below, and form top to bottom and across, which contain and in the second final position of the strings will be examined. From a semantic relationship between items before and after and within each string, the first two will be called synonymous type and the last, complementary type.

\subsection{Synonymous Type}

Complex prepositions, up and above and down and below, are called synonymous type because the semantic relationship between elements before and after and within each string is synonymous. Although we can recognize this quite similar semantic relationship in elements within strings, meanings of the two entire expressions are quite the opposite.

In the following, distribution patterns of up and above will be examined first.

\subsubsection{Up and Above}

Cases in which the string appears in major functions that prepositional phrase, in which up and above will be the head, may perform will be sited one by one. The use as prepositional adverb will be taken up at the last of this section.

In its original sense, up and above indicates the direction toward the opposite of gravitational force. In numerical terms, this means bigger. In metaphorical sense, this means better.

\subsubsection{Predicative Nominal Modifier}

(1) For a while, the return climb doesn't seem all that bad - a gradual rise up and above a small stream, through a neat hardwood forest.

http://www.roanoke.com/outdoors/hiking/43059.html, retrieved 2012/3/10

(2) The small opening at the bottom of the sinkhole opens up into the "ceiling" of the cave 66 feet up and above a huge pile of breakdown.

http://vtrail.com/byalphabet/ctrails/caveridge.html, retrieved 2012/3/10

(3) Whilst you may ideally be after a model up and above a 42 inch LCD TV, don't go sacrificing quality for size when your budget is limited.

http://ledhdtvtelevisions.com/lg-37-inch-1080p-lcd-tv-review-37ld450/, retrieved 2012/3/10

(4) Are there administrative fees or other service charges up and above the property management and leasing fees?

http://www.definiteanswers.com/q/Are-there-administrative-fees-or-other-service-charges-up-and-above-the-pro perty-management-and-leas-4dd4f5a1df259, retrieved 20123/3/6

\subsubsection{Intransitive Verb Complement}

(5) Just plant higher growing plants that will grow up and above the squash or the squash may smother them out or prevent them from getting proper light. 
(6) When the faster (thicker) moving average is moving up and above the slower (thinner) moving average the trend is up, and when it is below the slower moving average and moving down, the trend is down.

http://www.financial-spread-betting.com/trading/gauging-the-trend.html, retrieved 2012/3/9

(7) If certain employees perform up and above the expectations and help the company to achieve better results, the organization would appreciate their efforts and give them a raise in their salary.

http://www.buzzle.com/articles/what-are-the-factors-affecting-performance-appraisal.html, retrieved 2012/3/9

2.1.1.3 Transitive Verb Complement

(8) Squeezing your chest muscles, extend your arms up and above your shoulders.

http://www.ehow.com/how_2279577_do-supine-chest-fly.html, retrieved 2012/3/11

(9) At Lupi, the decision to build homes up and above our usual exceedingly vivid standards means you truly are buying a luxury home.

http://lupihomes.com/Dream+Planning.html, retrieved 2012/3/11

(10) That philosophy along with over 100 years of combined marine service experience is what sets Portage Lakes Marine service up and above all competitors.

http://portagelakesmarine.com/service.aspx?isOn=3, retrieved 2012/3/11

2.1.1.4 Prepositional Adverb

(11) Learning to fly is an exciting and rewarding adventure. It gives you the freedom to get up and above.

http://www.tulsaflightinstruction.com/learning-to-fly/, retrieved 2012/3/11

(12) He then went up and above to improve our sprinkler system.

http://irrigationanddrainage.mobi/, retrieved 2012/3/11

(13) Sam has made our furniture selection so easy and has gone up and above to satisfy our needs as customers!

http://www.gardner-white.com/products/product.php?productId=25558, retrieved 2012/3/11

\subsubsection{Down and Below}

The entire meaning of the string is the opposite of up and above. The original meaning is toward the direction of gravitational force. In numerical terms, this means smaller or lesser. In metaphorical sense, this means lower.

2.1.2.1 Predicative Nominal Modifier

(14) Here, many decks down and below the waterline, four men were on watch in the lower steering position, http://ww2today.com/13th-november-1941-hms-ark-royal-sunk, retrieved 2012/03/21

(15) Start at the left side of the wall just to the right of the easy way down and below a wide crack.

http://www.javu.co.uk/Climbing/NewRoutes/WestCornwall_SouthCoast.shtml, retrieved 2012/3/20

(16) This remarkable spring water is sourced from an ancient spring 300 meters down and below the natural filtration beds of limestone rock synonymous with this region of Ulster.

http://www.celticpure.ie/about-us, retrieved 2012/03/21

2.1.2.2 Intransitive Verb Complement

(17) Regulators should be installed with the vent facing down and below a protective cover.

http://www.grill-repair.com/blog/2009/grill-parts-regulator/, retrieved 2012/3/20

(18) It is also known to change its characteristics, and become more brittle when the temperature goes down and below a certain temperature.

http://brage.bibsys.no/uis/bitstream/URN:NBN:no-bibsys_brage_21431/1/Opsahl\%20Steigen,Ragnhild.pdf, retrieved 2012/3/20

(19) The opposite also holds true, as the short moving average crosses down and below the long moving average, a new downtrend may emerge in the near future.

http://www.fxwords.com/m/moving-averages.html, retrieved 2012/3/21

2.1.2.3 Transitive Verb Complement

(20) Take the top layer and wrap it down and below the other layer. 
http://www.ehow.com/how_8250230_tie-fashion-scarf.html, retrieved 2012/3/21

(21) Drag the top center control handle (the small black boxes) down and below the current text.

http://www.xaraxone.com/webxealot/workbook22/page_5.htm, retrieved 2012/03/21

(22) Corn futures ended the week down and below mid March levels.

http://traderkingdom.com/futures-basics/2382-corn-market-experiences-price-swings-on-volatile-usda-report, retrieved 2012/3/22

2.1.2.4 Prepositional Adverb

(23) After awhile the sun was starting to go down and below is one of those shots.

http://vnsphotography.com/, retrieved 2012/12/4

(24) All committee members stood down and below are the elected officers

http://www.doultingskittles.co.uk, retrieved 2012/12/4

(25) Top door opens down and below are two doors which open out.

http://prod20.mythings.com/portfolio.aspx?userid=95818, retrieved 2012/12/6

2.2 Complementary Type

2.2.1 From Top to Bottom and Across

From top to bottom and across has a very intricate structure. The first item before and, from top to bottom, is in itself an idiomatic expression. This expresses vertical dimension of space. The second item, across, expresses horizontal dimension of space. Thus the two complement each other in semantic space.

In physical terms, this preposition indicates the whole expanse of any two or three dimensional objects. In metaphorical sense, this means encompassing everything inside.

2.2.1.1 Predicative Nominal Modifier

(26) Can you please tell me the measurements from top to bottom and across the chest?

http://www.ebay.com/itm/Mens-XXL-Vineyard-Vines-Wool-Sweater-/160706200966, retrieved 2012/3/11

(27) The buttons measure 7/8" $(2 \mathrm{~cm})$ from top to bottom and across the widest part.

http://www.etsy.com/listing/19350511/sale-porcelain-heart-buttons, retrieved 2012/3/4

(28) Stakeholders from top to bottom and across the organization have to be engaged and aligned.

http://theoneresourceyouneed.com/theoneresource/index.php/extras, retrieved 2012/3/11

(29) A complete transformation of the IT infrastructure from top to bottom and across business units was necessary so that we could continue to provide the best systems available.

http://www.sap.com/press.epx?pressid=8247, retrieved 2012/3/11

2.2.1.2 Intransitive Verb Complement

(30) Figure 1a is a cross-sectional view with contours indicating how velocity varies from top to bottom and across the stream channel.

http://www.colorado.edu/geography/courses/geog_2043_f01/lab01_2.html, retrieved 2012/3/11

(31) The frame is well-designed and supported overall with leather tension strapping going from top to bottom and across the waist.

http://outyourbackdoor.com/article.php?id=1076, retrieved 2012/3/11

(32) For inside the window frame, measure from top to bottom and across the top and center of window. http://www.doityourself.com/stry/how-to-make-relaxed-roman-shades, retrieved 2012/3/11

(33) The measurements are from top to bottom and across the widest part of the piece, not including the Bail. http://www.delphiglass.com/gallery/store_viewItem?gid=9337, retrieved 2012/3/4

2.2.1.3 Transitive Verb Complement

(34) Heated air flows in a 3608 pattern uniformly across the spiral conveyor from all sides, providing consistent temperature from top to bottom and across the belt on each tier. 
http://my.packexpo.com/pei2010nn/public/Booth.aspx?IndexInList=\&Upgrade=\&FromPage $=\&$ BoothID $=10518$ 7\&Task=ProductsDetails\&PRODID=7856,retrieved 2012/3/11

(35) POWER-TRAC IR protects people and objects by sending infrared signals from top to bottom and across closing aisles.

http://www.tabopg.com/mobile.htm, retrieved 2012/3/11

(36) But by 1918 firepower had been integrated with protective cover and mobility, in the form of tanks and military aviation, and had been complemented by the use of radio to open the lines of communication and facilitate alignment from top to bottom and across units.

http://www.forbes.com/sites/forbesleadershipforum/2011/08/23/world-war-is-crucial-lesson-for-todays-leaders/, retrieved 2012/3/11

2.2.1.4 Prepositional Adverb

(37) The trellises, arbors, and artificial trees have clear mini lights intertwined from top to bottom and across for a sparkling effect.

http://www.christmas-light-source.com/Clear-or-White-Mini-Lights_c_104.html, retrieved 2012/3/11

(38) The stone measures $3 / 4$ from top to bottom and across.

http://www.etsy.com/listing/43683487/blue-peruvian-opal-ring, retrieved 2012/3/11

(39) A major factor which must be considered, if the benefits of leadership are to be given full rein in an organization, is the existence of a good communications system, from top to bottom and across.

http://www.bizmove.com/skills/m8m.htm, retrieved 2012/3/11

\section{Conclusion}

All three strings occur in major functions where single word prepositions are used. In addition, they can be used as prepositional adverbs. This strongly indicates the cohesion of these strings as single units. What these corpus data show is that they are forming some kind of units of their own and that their behavior, in syntactic terms, is very close to that of single word prepositions. Thus, these strings may well be considered complex prepositions.

\section{Further Questions}

\subsection{Synonymous Type}

\subsubsection{Strings without And}

Both complex prepositions have corresponding strings without and. Although their occurrences are rarer than those with and, they can be used in the same syntactic positions including prepositional adverb positions. Consider the following:

(40) Scientific analysis has confirmed that oil bubbling up above BP's sealed Deepwater Horizon well in recent days is a chemical match for the hundreds of millions of gallons of oil that spewed into the Gulf last summer.

http://www.floridaoilspilllaw.com/confirmed-oil-bubbling-up-above-macondo-well-is-chemical-match-to-bps-cr ude-says-noaas-ed-overton-photos/, retrieved 2012/3/12

(41) However, this time, the RSI popped up above 70, and shows bullish momentum, although the near-term may be overbought.

http://www.ibtimes.com/articles/290004/20120130/nzd-usd-nzdusd-uptrend-asian-session.htm, retrieved

$2012 / 3 / 10$

(42) I could still hear pieces of masonry crumbling around me, and I said a silent prayer that the next one to fall wasn't the one that was holding half a building up above my head.

http://yearofstories.wordpress.com/2011/10/25/day-one-hundred-and-fifty-seven-killing-time/, retrieved

$2012 / 3 / 20$

(43) Holding the camera straight up above, more and different patterns appear . . . . and then looking down to the horizon, the sky, of course, goes on forever.

http://juliafoggterrain.wordpress.com/2012/02/28/up-above/, 2012/3/10

(44) The top number north of the line is called the numerator and the number down below the line is the denominator. 
http://resourcefiles.learnzillion.com.s3.amazonaws.com/, retrieved 2012/12/7

(45) Now, since most don't have the TBL or Chart mode, what you want to wait for is price to fall down below the trigger number and them move back up towards in with No Demand.

http://www.forexfactory.com/showthread.php?p=6268921, retrieved 2012/12/7

(46) I have been wanting to float my kayak down below Denison dam.

http://texasfishingforum.com/forums/ubbthreads.php/topics/8305114/Re_Cat_fishin_below_Denison_da, retrieved 2012/12/7

(47) The building will have 74 (likely very expensive) dwelling units up top, with 404,000 sq.ft. of office space, and retail down below.

http://sfist.com/2012/12/05/yay_another_tall_tower_in_the_works.php\#photo-1, retrieved 2012/12/7

From the standpoint that every change in surface structure conveys some kind of change in the massage that the string expresses, there should be some differences between the two corresponding strings with and without and. Data are still limited to decide what these differences are. Further research into this question should be needed.

\subsubsection{Over and Above and Under and Below}

Although quite scarce, we find strings in which the first prepositions are replaced by over or under.

(48) As the short moving average crosses over and above the longer moving average, this can be interpreted as a change in trend to the upside.

http://www.fxwords.com/m/moving-averages.html, retrieved 2012/03/26

(49) I'm having lots of issues with my layout but my most immediate need is to move my top navigation over above my content area instead of above my left navigation bar.

http://wordpress.org/support/topic/top-navigation-moving-it-over-above-content-area, retrieved 2012/3/21

(50) The left side of my neck hurts under and below my jaw.

http://www.justanswer.com/medical/2wxzf-left-side-neck-hurts-below-jaw-seems.html, retrieved 2012/3/23

(51) I followed Hello Views, Google Map View and now I want to add a TextView under below the MapView.

http://stackoverflow.com/questions/4143858/how-can-i-add-a-textview-below-a-mapview, retrieved 2012/03/24

Whether they are faulty extensional uses of the strings with up or down, or well-established complex lexical entities of their own is the question we need further study.

\subsection{Complementary Type}

\subsubsection{Grammaticalization Level of the String}

We found two examples which indicate that unity between the first element, from top to bottom, and the second element, across, might be weaker.

(52) The idea is to break your photo up into thirds both from top to bottom and across.

http://www.digital-photography-advisor.com/rule-of-thirds.html, retrieved 2012/3/11

In this example the two elements are separated by the expression, both . . and . . ., indicating independent nature of the two elements.

(53) The main difference between a cluster outline and a formal outline is that it is not linear; it doesn't necessarily run down a page from top to bottom and across from left to right.

http://www.odessa.edu/dept/english/mjordan/outlining.htm, retrieved 2012/3/11

In this example, the second element, across, is modified by the phrase, from left to right. This highlights the contrasting nature of the second element against the first element, from top to bottom.

What these instances indicate is that this string is in its intermediate stage of grammaticalization and that there still remains a certain amount of lexical freedom in elements inside the string.

\subsubsection{Top to Bottom and Across}

We found two examples without the string initial preposition, from.

(54) My 25-plus years in technology have earned me the luxury of experience in a number of different work environments, and I've learned how intercommunication works at all levels - top to bottom and across all 
employees.

http://www.forbes.com/sites/davidroth/2012/10/31/transparency-across-the-ranks-can-they-handle-the-truth/, retrieved 2012/12/8

(55) The fact that he was able to redesign American commerce top to bottom and across is really stunning. http://www.voanews.com/learningenglish/home/Steve-Jobs-Remembered-131419558.html, retrieved 2011/10/10 The frequency rate of this string is quite low, so we will have wait and see whether this string is well-established as a complex lexical item.

\section{References}

Crystal, D. (1980). A First Dictionary of Linguistics and Phonetics. London: Andre Deutsch.

Hoffmann, S. (2005). Grammaticalization and English Complex Prepositions: A Corpus-based Study. Oxon: Routledge.

Hopper, P. J., \& Traugott, E. C. (1993). Grammaticalization. Cambridge: Cambridge University Press.

Hopper, P. J., \& Traugott, E. C. (2003). Grammaticalization (2nd ed.). Cambridge: Cambridge University Press. http://dx.doi.org/10.1017/CBO9781139165525

Inoue, A. (2012). Newly observed phraseological units functioning as group prepositions in contemporary English: The case of be on against and in and of itself. A presentation read at the 5th meeting of Japan Society for Phaseology held at Umeda Campus, Kwanseigakuin University, Japan on March 3, 2012.

Leech, G., \& Svartvik, J. (1975). A Communicative Grammar of English. London: Longman.

Leech, G., \& Svartvik, J. (1996). A Communicative Grammar of English (2nd ed.). London: Longman.

Leech, G., \& Svartvik, J. (2002). A Communicative Grammar of English (3rd ed.). London: Pearson.

Quirk, R. et al. (1972). A Grammar of Contemporary English. London: Longman.

Quirk, R. et al. (1985). A Comprehensive Grammar of the English Language. London: Longman.

Quirk, R., \& Greenbaum, S. (1973). A University Grammar of English. London: Longman.

Quirk, R., \& Mulholland, J. (1964). Complex prepositions and related sequences. English Studies (Supplement; Frstschrift for R. W. Zandvoort), 45, 64-73. http://dx.doi.org/10.1080/00138386408597188 